\title{
Testing Goodwill: Conflict and Co-Operation in New Product Development Networks
}

\author{
By \\ Anne-Marie Coles, Lisa Harris, Keith Dickson \\ School of Business and Management, Brunel University, Uxbridge, UB8 3PH, UK \\ Published in \\ International Journal of Technology Management, 25(1/2):51-64, 2003
}

\begin{abstract}
Network forms are often seen as models of organisational flexibility, promoting the building of trust and exchange of information between different business functions while offering both cost savings and reductions in the uncertainties usually associated with innovation. Both internal and external networks have been identified as key elements in the collaborative development of new products. The actual process of network building and ongoing network management is not well researched, although the existing literature highlights difficulties for organisations attempting to maintain active product development networks. This article examines the development and management of such a network in the defence industry and focuses on network building processes in terms of the interactions between the individuals involved. This network has endured and evolved over many years despite a series of conflicts. One of the key findings is that the effective functioning of the overall network is closely allied to established processes within the two participating firms.
\end{abstract}

\section{Key Words}

Innovation Networks, New Product Development, Organisational Politics, Network Building, Management of Networks 


\section{Introduction}

The article begins with a brief review of literature on the nature of innovation networks, before considering the challenges of managing conflict and co-operation within networks. It then focuses on a case study of a long-term collaboration between two firms in the defence industry. One firm is based in the UK, the other in the USA and they are jointly developing state-of-the-art electronic receivers. The nature of innovation networks is examined through the study of their relationship going back some 15 years between firstly, internal and external networks and secondly, formal and informal network modes. The connection between network success and organisational growth is considered in the light of possibilities for long-term learning and adaptation. One of the key findings is that the effective functioning of the overall network is closely allied to the dynamic interactions within and between the two participating firms.

The methodology employed in researching the case presented here involved over thirty face-to-face interviews with network participants from both sites, over a eighteen month period. The generous level of access to employees across a range of functions and hierarchical levels enabled the construction of a detailed case biography encompassing a wide range of perspectives. Accounts from individuals who had been involved in the network virtually from the time of its creation, together with accounts from people who had joined more recently, ensured that a thorough analysis of the factors affecting learning and change within the network could be undertaken.

\section{The Nature of Innovation Networks}

There is a growing interest in investigating the function of networks in innovation. One strand of thought has considered the role of internal networks in technological development, and had focussed on the flexibilities intrinsic to this form of organisation enabling the firm to respond to rapidly changing conditions [1]. The literature identifies factors such as improved communication between different business functions [2], effective new product development through alliance-building [3], and organisational learning as positive outcomes of networking [4]. Other writers, however, not only look at the positive role networks play in the innovation process, but also at the restrictions and contingencies they may impose [5]. For example, embedded and increasingly dysfunctional networks [6], resistance to 
change [7] and poor information sharing across the networks [8] have been identified as critical problem areas . Coombs and Hall (1998) suggest that both formal and informal networks are involved in the effective diffusion and utilisation of organisational knowledge throughout the firm, raising the issue of possible 'legitimate' routes of information flow [9].

In addition, the implications of external alliances and networks for innovation have been analysed in terms of cost savings [10], control of technological uncertainties [11] and knowledge capture from external sources [12]. Small, highly innovative firms in particular, may rely on 'flexible specialisation' [13], which makes external networking essential to their survival [14]. Informal external networks have been identified as critical in knowledge sharing processes [15] and the generation of new ideas [16]. Lundgren (1995) has shown that embedded external networks can inhibit changes between customers and suppliers [17], while other risks have been identified for small and medium sized firms, including imbalances of power[18], loss of technological 'know-how' [19], increased network dependency, and resource demands [20]. Hakansson and Johanson (1988) noted, however, that technical, legal and social bonds can develop between network participants which can help to stabilise external linkages [21].

Some writers have shown the dependence of innovative firms on both internal and external networks to facilitate a complex programme of new product developments [22]. Such networks may be formal or informal in nature, or a even a combination of both. Informal networks are characterised by information exchanges between individuals based on social exchange, for example overlapping areas of interest or concern whether professional or personal. Formal networks, however, typically involve cross-functional communications between representatives from different departments or from their respective organisations. Ring and Van de Ven (1994) draw attention to this distinction in roles between formal representation and informal, interpersonal interactions within networks and also point out that both types of interaction are important in building trust and co-operation between network participants [23]. Other writers have also noted an relationship between formal and informal network processes [24].

It can be seen from the above discussion that much of the literature has identified the effects of networks on innovation in terms of either facilitating or obstructing the process of technological development. Less attention has been paid to the factors which impact on the actual network building processes [25]. However, the process of network building is a politicised activity with key interest groups influencing cooperative and conflictive agendas, and investigating the role of negotiation in creating and shaping 
management decisions may expose areas of vulnerability in inter-organisational innovation projects. As Eld and Johansson (1997) observe, 'powerful firms exploit their network position to obtain favourable conditions of exchange' [26]. Pfeffer (1992) highlights the role of power in influencing organisational behaviours through the interdependence of disparate groups, creation of coalitions and the development of communication networks [27]. Morgan (1997) attempts to explain conflicting objectives and interests of individuals as they seek to affect the outcomes of organisational change, by that loose networks of people will 'co-operate in relation to specific issues, events or decisions or to advance specific values and ideologies'[28]. Dawson (1994) considers the political nature of change and the actions of 'change agents' in terms of the social construction of past decisions and their implementation [29]. The competence and expertise required in building and maintaining innovation networks depends on the capacity of managers to confront and resolve issues arising from the interactions between network members, and such activity highlights the ability of management to shape organisational outcomes of technological change. Termed the 'process agenda' by Buchanan and Body (1992), such negotiation is illustrated in the case study that follows [30].

A key dynamic of network development therefore, appears to be the desire to advance and defend selfinterests on the part of the participants. In the case study that follows, it will be argued that effective product development has relied on changing aspects of network organisation. It appears that successful product development through an inter-firm network may be constantly under threat from changes to the internal organisation in both firms. While the nature and characteristics of the product developed are specified down to the finest detail by the customer, it is contended here that the success of the development process is highly dependent on various levels of interaction between the network participants. Furthermore, the longitudinal nature of this case helps to illustrate more dynamic aspects of the processes involved in network building and its management. 


\section{The Case Study}

The case consists of two firms working in the defence industry which have been collaborating since 1985 over the development of receiver technology that forms part of military communications systems. The network is composed of representatives of different business functions in the two firms, though its composition does not stay constant as both the departmental and individual roles in the network change over time. There exists a formal agreement over the collaboration, within which two contract teams are involved in putting together project bids while engineers in both firms fulfil specific development tasks involving a significant amount of knowledge transfer. The UK firm is well established in the UK defence electronics market as part of a electronics group consisting of 12 firms based in the UK and the USA. One division (referred to here as $\mathrm{HCo}$ ) maintains a network-based innovation strategy through the development of technological collaborations with other firms [31]. The initial collaboration with a small firm in the USA (referred to here as FCo) was an early example of this partnering strategy, and is now one of the longest running on-going collaborative projects in which the two firms are involved. The network under study, therefore, consists of employees in both firms interacting both at formal and informal levels.

As early as 1985 senior managers at $\mathrm{HCo}$ first approached FCo with a proposal for collaboration. Development work undertaken at FCo at the time related to the production of electronic receivers for the US Navy. HCo was keen to utilise this expertise to reduce its own costs in developing a similar product for the UK Ministry of Defence (MoD), while FCo would not have been able to bid for participation in a $\mathrm{MoD}$ contract without a suitable UK partner. Initially a HCo management team was sent into FCo to assess the facilities and production quality standards, and it was sufficiently impressed to offer a licence fee in exchange for the technical information and specialist assistance required to develop the product in the UK. HCo had experience in supplying avionics equipment for helicopters and knowledge of the UK defence market that was instrumental in the partnership winning the MoD contract despite strong competition. The two firms implemented a manufacturing licensing agreement to cover limitations on territory as well as sort out the 'work share' arrangements. By teaming with FCo, HCo was able to reduce its own product development costs while the arrangement gave UK market access to a small US firm, so managers from both sides expected mutual benefits to accrue from this partnering arrangement. 


\section{HCo / FCo Partnership - the Early Years}

A good working relationship developed in the early stages, and HCo was able to spread its costs further by delivering similar products under other contracts alongside the work with FCo. However, cultural differences in the way business is done in the US and the UK caused some difficulties in day to day dealings between the two firms, as did some clashes between individuals. Effective working relationships that did develop often lacked continuity due to periodic changes in responsibility and staff turnover. Organisationally, FCo was perceived to be poorly run, had a bad record in meeting deadlines and delivery, and was also working within very tight financial constraints. Communications between the two firms became more fraught as time went on. These operational difficulties led to increasing friction and acrimony between them, because HCo incurred the wrath of the ultimate customer for late deliveries or technical problems. Very soon, HCo felt that the US firm had too relaxed an attitude to both deadlines and contractual requirements, and this caused problems for UK engineers who spent a considerable time in ensuring the technology met the detailed specifications in the highly specific contract from the MoD.

A major problem emerged when FCo was subsequently taken over by another US firm and a new management team was put in place. The new Chief Executive Officer opposed the collaboration and one of his first acts was to remove the Marketing Officer who had initiated the collaboration with HCo. In addition, a number of other key employees left, including some of the engineers involved in development of the receiver technology. Meanwhile, FCo's contract to supply the receiver in the US (the design of

which was the basis of the joint MoD project in the UK) was re-tendered by the US Department of Defence (DoD) [32]. Thinking that this was just a contingency plan, FCo managers suggested that HCo should also bid for the 'second source' contract as they preferred the idea of sharing the business with a known firm. But changed federal contractual terms gave rise to a situation where the two firms ended up competing head-to-head for the business, which not surprisingly caused some friction. FCo won this business but internal management problems contributed to an over-commitment of resources and consequently the firm's already precarious financial problems were exacerbated.

As a result of this experience, the fragile relationship between FCo and HCo broke down completely, with HCo quite sure that its bid had contributed to the developing problems of the other firm. This bid had also given HCo the impetus to put more resources into its own internal technological developments and this 
effort to rival the erstwhile partner had gone some way to make up its earlier technical deficiency. But it also illustrated to HCo the vast level of investment in terms of cost and technical resources that would be needed to continue development of its own version of the receiver. Nevertheless, two different versions of the technology were now a distinct possibility. Staff interviewed at HCo recalled an atmosphere of increasing frustration at the unreliability of FCo and the damage caused by competing with them was regarded as the final straw, even though some parts of the complex network were still functioning cordially. FCo, however, was preoccupied with continuing organisational and financial problems.

\section{The Path to Takeover}

By the early 1990s, FCo had started to develop a new generation of its receiver technology, and HCo was keen to gain access to the new development. They felt FCo was considerably ahead of any comparable technology worldwide including their own and co-operation would be essential in bidding for another proposed MoD project. However, there were worries about the headstrong nature of the CEO at FCo whose management style was perceived to be, 'uncontrollable'. Because of the acrimonious ending of the earlier relationship and the breakdown of trust between the firms, HCo was very cautious when entering into partnership negotiations again in 1996, so much so that the whole contract team was sent on a course to develop their negotiating skills in advance. FCo was still perceived as technically excellent, organisationally poor, financially weak, and habitually late in delivery. Consequently a new partnership was regarded as a major risk but if the US firm reneged on a new agreement, HCo felt it would be in a stronger position than in the 1980s when it did not have the in-house expertise to cope with the technology. It was clear that resurrecting the alliance was a 'necessary evil' and therefore contingencies would have to be built into the relationship to allow for expected delays and missed deadlines on the part of FCo.

However, despite the expectations that a mutually acceptable agreement between the firms might not be possible, negotiations turned out to be less fraught than expected and an memorandum of understanding was quickly signed, as HCo was also able to bail FCo out of severe financial difficulties at that time. The re-formed partnership was awarded another MoD contract in early 1997.

The renewed collaboration was taken a stage further a few months later when the HCo group took over FCo. According to $\mathrm{HCo}$, the idea of purchasing the US firm stemmed from the perceived need to control 
'loose cannons' within FCo's management structure, who had contributed to the relationship breakdown. Interviewees from FCo claimed that their senior management had approached HCo at the Farnborough Air Show seeking a 'white knight' because the financial position had become so grave that the company may well have otherwise gone into receivership. HCo would also have then lost its newly resurrected US partner and the lucrative MoD contract would have been placed in jeopardy. The relationship could also have been doomed if FCo had been taken over by a hostile firm. The $\$ 13$ million deal was concluded in May 1997 and FCo now operates as an HCo subsidiary. A condition of the deal was the departure of the unpopular CEO [33]. HCo also insisted on one of its own senior managers being permanently based at the US firm's offices, although his influence is somewhat restricted due a special security agreement (SSA) enforced by the US government because of FCo's access to classified material. This tightly regulates the contact between FCo and HCo personnel, causing considerable operational difficulties at all levels. Hence despite its ownership of FCo, HCo has only very limited knowledge of the nature of its business with other US firms [34].

\section{Operational Implications of the Take-over}

Respondents at FCo openly acknowledged that their firm had tended to act in an impulsive and undisciplined way in the past, leading to a poor business reputation, and that the arrival of HCo had brought much-needed stability and organisation. HCo, with its conservative attitudes and firm cost controls, now brought in a sense of commitment and customer focus to FCo. This policy is greatly admired in FCo, and many of the employees interviewed claimed that the atmosphere in the firm was now less frantic and it was a much more friendly place to work. They described how several key staff - who had left the firm in frustration with the idiosyncratic CEO - had now rejoined and could not believe the transformation.

HCo has a very traditional culture with a hierarchical management structure that accords respect to length of service and educational achievement. One FCo interviewee was impressed by the efficiency and evident success of the UK operation, but he claimed that he always 'had to be on my best behaviour' when visiting the UK. In contrast, FCo is more informal, with everyone on first name terms and an 'open door' policy extending right to the top of the organisation [35]. FCo staff are impressed when they phone the UK in their afternoon and people are still at work, late into the UK night. Conversely some HCo staff perceive FCo staff to be idle because they would phone at $6 \mathrm{pm}$ US time and no one would be there. An 
undercurrent of resentment was evident in some of the more junior HCo employees, that FCo staff have a 'better deal' and go home early leaving HCo to sort out their mistakes. After visiting both firms, it is apparent that FCo staff start very early and work through without a break, whereas HCo staff start later in the day, have a long lunch break, and then stay on later in the evening. The strategy of sending a senior manager out from the UK for a two year period to manage the relationship helped to smooth over the cultural differences between the firms. The idea was that FCo would then be equipped to operate on its own as an HCo subsidiary after this trial period [36].

Some operational differences still persist. Testing of new systems is one such area. In the UK it is more extensive and linked to future production problems with an attempt to iron out any potential problems at an early stage. In the US testing is regarded as part of engineering and completed before production is involved. These unresolved divisions between the two engineering sites has left this section of the interfirm network dissatisfied with the level and type of communication, and the UK engineers, at least, believe, 'if we had not bought FCo, everything would have been cut and dried in terms of responsibilities now it's all blurred'. Some staff commented that FCo's emphasis upon speed of production to enhance short-term cash flow compromised the ultimate quality of the product. So there still appears to be a tendency to blame the US firm for production problems that occur.

Within HCo some believe that FCo employees might well perceive the take-over as a personal threat and be suspicious of collaborating with HCo staff. Consequently many HCo staff appeared sympathetic and willing to tolerate teething problems while allowing time for bridges to be built and a degree of trust established. One HCo manager felt that this factor could explain why FCo was reluctant to hand over any more than the minimum technical information. Some HCo employees reported that they had established a good working relationship with their counterparts, and they also noted how the time difference between the US and UK helps in turning queries around quickly and hence improved productivity. At the operational level, the HCo employees have seen the earlier customer/supplier relationship change to something more collegiate where all the staff ultimately work for the same boss. Staff from both firms acknowledged that synergies were developing as a result of the two sets of engineers working closely together. It is widely recognised that $\mathrm{HCo}$ is better at concepts, while FCo is more skilled in the operational detail, and this variable is now being exploited for mutual benefit.

The senior management team at HCo consider it to be more difficult to manage the relationship now than before FCo was purchased. Some interviewees from FCo admitted that they tend to be more casual about 
deadlines now that $\mathrm{HCo}$ is no longer a customer, and therefore give priority to other, more pressing projects. HCo staff felt that it was difficult to ascertain what progress FCo is making, because its staff often appears to be cagey about sharing information about the extent of other commitments. One felt that confidentiality was used as an excuse to keep HCo out of the development stage, and asserted that FCo engineers are secretive, competitive and just trying to protect themselves by keeping as much work as possible. The FCo engineers complained that they had no specific 'road map' to work to on the UK contract now that they were part of the HCo group rather than an independent supplier. They claimed that the lack of clear guidelines sometimes led to operational difficulties, but at the same time they were glad that HCo was too far away to interfere too much in their day-to-day activities.

They also realised that FCo could benefit financially from the new ownership structure. This is because it is now in HCo's interest to pay FCo promptly for work done, thereby improving the US firm's financial position. FCo is therefore in an unique position because it is effectively reporting to its biggest customer. While HCo wants FCo to be profitable, hence remaining a secure source of supply and justifying the decision to purchase, at the same time it wants to minimise the cost of the product at the UK end. Whilst acknowledging the greater rigour that the HCo approach has brought to their operations, some FCo interviewees were resentful of the degree of interest HCo showed in the detail of their business. In the words of one engineer,

'I wish we could just say "trust us, we are the experts". But they always make us feel that we have got something to prove, and cannot be trusted. I guess that goes back a long way though'.

The current position is that development for the MOD is well underway and the relationship between FCo and $\mathrm{HCo}$ is improving at the operational level. The original arrangement when the relationship between the firms was restored was that production for US contracts would take place in the USA, and UK contracts would be produced in the UK. However, FCo has recently been charged with product development for the MOD contract due to spare capacity. This decision was taken after a protracted delay and caused considerable ill feeling and fears over job security at HCo. In particular they fear the slippage of deadlines affecting time available for the final testing stage, for which the UK team have to plan and build required facilities, and would like to incorporate a range of features that experience has shown, will be necessary. The passage of time means that fewer staff are aware of the chequered history of the relationship and many of the main protagonists are no longer involved. Conflict between the firms is now internalised following the purchase of FCo, and its continuance can only be detrimental to the performance 
of the Group as a whole. It appears that FCo is well on the way to being absorbed into the HCo group, and its staff have job security and a constructive working environment for the first time in many years. The problem for HCo now centres upon the degree of resources that have to be devoted to managing the relationship with FCo and the increasing number of other partner firms around the world. It is recognised within the firm that the task is becoming increasingly onerous as the firm grows, and this issue is discussed in the next section.

\section{Discussion: The Role of Network Building Processes}

It has been suggested elsewhere [31] that HCo has developed a sophisticated expertise in long term management of inter-firm boundaries in response to its own extensive network of technological collaborations. It appears that HCo would rather take on the task of managing an uncertain partner boundary situation by developing high level negotiating skills, in preference to developing an in-house expertise which could result in the problem of creating what more than one respondent referred to as engineering 'idle time'. In other words, staff who are under-occupied during quiet periods are generally seen within the firm as a waste of resources and investment. In addition, HCo has failed to find any other comparable technology elsewhere and become dependent on the FCo receiver technology. Purchasing FCo was therefore essential to safeguard access to expertise when it appeared that the firm might have been in danger of bankruptcy or hostile takeover. The question has been posed whether network forms of association are enduring, or merely a prelude to takeover [37]. It is evident that the reasons for takeover in this case (as opposed to the many other long-term alliances with other firms managed by HCo) is that the expertise provided by FCo had become part of HCo's necessary core competence [38] because of their reluctance to develop an independent in-house technology. From HCo's perspective, the firm has now internalised the expertise necessary to maintain a leading position in the world market. In the words of one manager,

'This has been bread and butter business for us for the past 25 years, and there is no way we could have done it alone. I know there have been problems with FCo in the past... and no doubt mistakes by both sides, but hopefully we've all learnt something from it.'

From the point of view of FCo, despite the well documented vulnerabilities of small firms with respect to collaboration and the dangers of takeover, this solution appears to have brought organisational benefits 
and saved it from a hostile takeover. The two engineering sites, however, appear to have very different views of the necessity for network interaction. HCo engineers now feel undervalued and threatened by the decision to site production at FCo, particularly as the work is for a UK contract. Despite this vote of confidence in FCo, the instances of suspicion and secrecy described earlier may indicate that similar fears are also prevalent amongst the US engineers. The UK engineers are forced to wait for a completed development stage in the US before their own role in the project can begin. Not surprisingly, they would relish an opportunity to engage in earlier, open exchanges with the other site. In one sense, however, the uneasy relationship must be seen as a product of the chequered history of the technical centres within the two firms, as ingrained competition is still evident.

Inter-firm collaborations set up a complex network of interactions between the staff employed in the two firms, both at the formal and informal levels. This case study illustrates the many complexities involved in the analysis of the role of networks in new product development. The literature on this subject may appear contradictory in terms of identifying the costs and benefits associated with network forms of organisation.

This case helps to focus on the relationships and processes involved in building and maintaining such a network over time, and aspects of persisting co-operation and conflict. Although the collaboration between the two firms was initiated in terms of expected mutual benefits, operational difficulties soon emerged which were exacerbated to the point of breakdown by the first take over of FCo and the introduction of a hostile CEO. Formal breakdown at this level resulted in a loss of access to the technology for $\mathrm{HCo}$ and led to the duplication of technology due to continued development in-house at HCo. However, informal co-operation and information sharing between the two contract teams persisted during this time, indicating that co-operative networking processes, where there is established trust and high levels of mutual interest amongst certain particular groups, is not easy to curtail.

Senior managers at HCo continued to require strategic access to the FCo technology and in the difficult situation that ensued, they realised that a new tight formal agreement was essential to protect their interests, to the extent of sending staff for formal training in contract negotiation. It transpired, however, that the financial strength of HCo was a crucial factor in the continuation of the collaboration and in HCo's ability to direct their acquisition of the US firm. While this move resulted in securing the technology for $\mathrm{HCo}$ and solving the problem of access at senior management level, there were on-going conflicts between employees at other levels. Suspicion and jealousies seemed to exist over perceived 'better' employment 
benefits in the USA, while the persistent lack of trust and communication between the engineers appears to be a long-term problem. This indicates that informal conflicts in network processes are also difficult to manage and resolve when accompanied by mistrust and a lack of communication. Furthermore, such conflicts can arise at any point or level in the network.

The progress in network interactions in this case illustrates a number of points with respect to the development of inter-firm relationships. Disruptions at senior management level can result in a breakdown of formal relationships between the two firms, but the split is not necessarily irretrievable providing both firms have overlapping interests over which they wish to renegotiate. Even so, past conflict undermined trust and the terms of the new formal agreement reflected this by establishing new boundaries. Even though there had been a formal breakdown in one part of network, however, it had not led to the severing of all informal interactions, as demonstrated by the continual exchange of information between the two contract teams during this period. This implies that a complex network is not controllable from one focal point. Indeed, both co-operation and conflict can persist throughout any difficult periods of change in the network. Such evidence indicates a blurring of Ring and Van de Ven's [23] distinction between formal and informal interactions in networks, by suggesting that informal interactions can develop out of formal business links and informal processes can and do affect formal business behaviour. Furthermore, the case also provides evidence that both entrenched co-operative and conflicting informal relationships can persist beyond the conclusion of formal links, as noted by Hakansson and Johanson [21].

In this example it is clear that changes in the network building process have affected the direction and pace of technological developments. The UK version of the receiver technology (as developed by HCo) was abandoned when the formal relationship with FCo was repaired. Consequently, the highly specified nature of the contract resulted in a high level of division in developmental responsibilities between the two firms, which in turn generated difficulties in the exchange of technical information and increased secrecy. The outcome of this conflict has been responsible for delay and lack of information in the UK on how the development is progressing. This has affected the ability at HCo to plan their own part of the contract responsibility, in terms of day-to-day work organisation. The major part of the innovation has been placed in the hands of FCo rather than in the UK technical department. A different organisation and management of the work such as a shared development, would have resulted in a different process of change and thus a different product. This in turn illustrates that even within a highly deterministic industry structure, 
development of an inflexible, highly specified product is still susceptible to organisational influences, and in particular network processes.

Changes of personnel and priorities have previously been identified as a problem area in technological collaboration [10]. However, the cordial relationship which endures at least between the two contract teams can be seen partly as an outcome of the need to strike an equitable deal, and also an awareness that a reputation for fairness facilitates the build-up of trust. These informal relationships appear to have been instrumental in continuing a flow of information between the two firms even during the period where formal relations were antagonistic and seem to have involved FCo employees prioritising informal relationships over the introduction of management directives to sever all communication links. Even periodic changes to the personnel involved on both sides has not interrupted or changed the friendly relationships that have developed in this area.

While several commentators have argued that larger firms often dominate and even shape the network to their own interests $[10,26]$, this case illustrates the changing fortunes, over time, for both the larger and the smaller firms. At the outset, the smaller firm with the key technology was definitely the more powerful partner in the relationship. However, over time, management problems left them organisationally weak and vulnerable, so that while HCo was technically dependent on them, it was eventually in a position to take control of the whole development process. Thus power relations were affected as much by the dynamic balance of complementary dependencies as by firmsize.

\section{Conclusion}

This case serves to confirm several of the issues raised in the literature in product development networks, considered at the beginning of this paper. Our conclusion is that conflict and co-operation can co-exist within a complex, dynamic network and this helps to explain why the literature identifies both benefits and barriers to innovation networks. In addition this case demonstrates that the formation of inter-firm product development networks is linked to both internal organisational and external factors. The former concerns such issues as strategic decision making, in-house expertise and knowledge management, while the latter relates, in this case, to the influence of military contracts which have pressurized the firm to seek overseas 
partners and have highly constrained technical specifications. This case clearly shows that both formal and informal networking processes are part of the social factors shaping the development of the technology. While the formal links have defined the division of technical responsibilities, the informal links have influenced the access to information about the progress of the project, knowledge sharing processes and ultimately the ability of both parties to carry out their share of the development.

The long and turbulent history of the network studied clearly illustrates the dynamic nature of network relationships over time, and demonstrates the need for ongoing and active network management. While a clear rationale for co-operation exists, old loyalties die hard and the spirit of competition still endures. This raises questions about the possibility for the management and control of informal co-operation or conflict between network participants. Network processes have been influenced by ingrained aspects of organisational cultures, management styles and established areas of expertise.

\section{Acknowledgement}

This article has been based on work carried out under the European Community Targeted Social Economic Research (TSER) programme, project number PL97-1084. The authors would also like to thank the case study firm for its generous degree of participation in this project. 


\section{References}

1. See for example: Ebers, M (Ed) (1999), The Formation of Inter-organisational Networks, Oxford University Press, 1999; G. Thompson, G., Frances, J., Levacic, R.. and Mitchell, J. (Eds) (1991), Markets, Hierarchies and Networks, Open University/Sage, London; Freeman, C. (1991), >Networks of Innovators: A Synthesis of Research Issues, Research Policy, 20(5):499-514; and Aoki, A. (1984), The Co-operative Game Theory of the Firm, Clarendon Press, Oxford.

2. For further discussion of these points see Moenart, R. \& Caeldries, F. (1996), 'Architectural Redesign, Interpersonal communication and Learning in R\&D', Journal of Product Innovation Management, 13(4): 296-310, 1996.

3. Kahn, K. B. (1996), 'Interdepartmental Integration: A Definition with Implications for Product Development', Journal of Product Innovation Management, 13 (2).

4. Dougherty, D. and Hardy, C. (1996) 'Sustained Product Innovation in Large Mature Organisations: Overcoming Innovation to Organisation Problems=, Academy of Management Journal, 39 (5):1120-1153; Anderson, N., Hardy, G. and West, M. (1994) 'Innovative Teams at Work', in Mabey, C. and Iles, P. (Eds), Managing Learning, Routledge, London and New York.

5. Walker O C (1997) The Adaptability of Some Network Organisations: Some Unexplored Questions, Journal of the Academy of Marketing Science, 25 (1):75-82.

6. Fletcher D (1998), Swimming Around in Their Own Ponds: the Weakness of Strong Ties in Developing Innovative Practices, International Journal of Innovation Management, 2(2):137-159; McLoughlin I, Badham R, \& Couchman P (1998), Implementing Vulnerable Socio-technical Change: Three Cases From Australia, in W Karwowski, R Goonetilleke (eds) Manufacturing Agility and Hybrid Automation -II,

7. Williams, R. (1997) 'The Social Shaping of a Failed Technology? Mismatch and Tent between the Supply and Use oFComputer-Aided Production Management', in C Clausen and R Williams (eds) The Social Shaping oFComputer-Aided Production Management and Computer-Integrated Manufacture, Proceedings from a European Community COST A4 Workshop, DTU, Denmark ; and Hislop, D. Newell, S. Scarborough, 
H. and Swan, J. (1997) 'Innovation and Networks', paper presented at British Academy of Management Annual Conference, London.

8. Adler P (1990), >Shared Learning=, Management Science, 36:938-957; Coles A-M, Harris L \& Jackson P, (1999), >Ignore Them and They=ll Go Away: the Failure of Process in Network Building=, Working paper, mimeo, School of Business and Management, Brunel University.

9. Coombs R \& Hall R (1998), >Knowledge Management Practices and Path Dependency in Innovation=, Research Policy, 27: 237-253.

10. Lawton Smith, H. Dickson, K \& Smith S (1991) 'There Are Two Sides to Every Story: Innovation and Collaboration Within Networks of Large and Small Firms, Research Policy, 20(5):457-468

11. Coombs R, Richards A, Saviotti P \& Walsh V (Eds) (1996), Technological Collaboration: The Dynamics oFCo-operation in Industrial Innovation, Edward Elgar, Cheltenham.

12. Hansen H, Koch C, \& Pleman A (1999), Small is Beautiful: Customer Driven Software Development, paper given at PICMET conference, Oregon, USA, July.

13. Piore M and Sabel C (1984) The Second Industrial Divide, New York, Basic Books.

14. For a discussion see Saxenian, A. (1991) 'The Origin and Dynamics of Production Networks in Silicon Valley', Research Policy, 20(5): 423-438; Rothwell R (1989), Inter-firm Relationships and Technological Change, Entrepreneurship and Regional Development, 1(3):275-291; Whittaker E \& Boner D (1994), >A

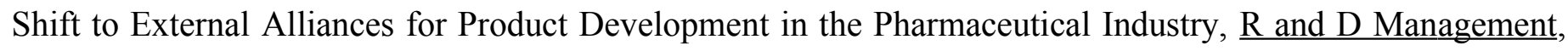
24: $249-259$.

15. Kreiner K \& Schultz M (1993), >Informal Collaboration in R\&D: The Formation of Networks Across Organisations , Organisation Studies, 14:189-209; Von Hippel E (1987), >Co-operation Between Rivals: Informal Know-how Trading, Research Policy, 16:291-301; Rappa M \& Debackere R (1992), >Technological Communities and the Diffusion of Knowledge, R \& D Management, 22:209-220. 
16. Steward F \& Conway S (1996), >Informal Networks in the Origination of Successful Innovations , in Coombs R, Richards A, Saviotti P \& Walsh V (Eds), Technological Collaboration: The Dynamics oFCooperation in Industrial Innovation, Edward Elgar, Cheltenham..

17. Lundgren A (1995), Technological Innovation and Network Evolution, New York, Routledge.

18. Doz, Y. (1988), 'Technology partnerships between larger and smaller firms: Some critical issues', in Contractor, F. and Lorange, P. (eds), Co-operative Strategies in International Business, Lexington, Mass.

19. Rothwell, R. \& Dodgson, M. (1991) 'External Linkages and Innovation in Small and Medium Sized Enterprises', R\&D Management, 21(2):125-137.

20. Szarka J (1990), Networking and small firms, International Small Business Journal, 8(2):10-22.

21. Hakansson, H, \& Johanson H (1988), Formal and Informal Co-operation Strategies in International Industrial Networks, in Contractor F \& Lorange, P. (eds), Co-operative Strategies in International Business, Lexington, Mass.

22. For example Pisano G (1990), The R\&D Boundaries of the Firm, Administrative Science Quarterly, 35:153-176; Tidd J (1995), Development of Novel Products Through Intra-organisational and Interorganisational Networks: the Case of Home Automation, Journal of Product Innovation Management, 12(4):307-322 ; Firth R \& Narayanam V (1996), New Product Strategies of Large Dominant Product Manufacturing Firms: An Exploratory Analysis, Journal of Product Innovation Management, 13(4);334-347.

23. Ring P \& Van de Ven A (1994), Developmental Processes oFCo-operative, Inter-organisational Relationships, Academy of Management Review, 19(1):90-118

24. For a more in-depth discussion of these points see Conway S (1995), Informal Boundary Spanning Communications and the Innovation Process: An Empirical Review, Technology Analysis and Strategic Management, 7(3):327-342 ; Robertson, M. Swan, J. and Newell, S. (1996), The Role of Networks in the Diffusion of Technological Innovation, Journal of Management Studies, 33 (3):333-359; Harris L (1999), Building Inter-firm Networks: A Case Study of Emc (SW) Ltd, International Journal of New Product Development and Innovation Management, 1(3); Arrighetti A, Bachman D \& Deakin S (1997), Contract 
Law, Social Norms and Inter-firm Co-operation, Cambridge Journal of Economics, 21:171-195; and Spekman R, Isabella L, MacAvoy T \& Forbes T (1996), Creating Strategic Alliances which Endure, Long Range Planning, 29(3); 346-357.

25. Harris L, Coles A-M, Dickson K \& McLoughlin I (1999), Building Collaborative Networks: New Product Development Across Organisational Boundaries, in Jackson P (Ed), Virtual Working: Social and Organisational Dynamics, Routledge, London..

26. Eld U and Johansson U (1997), Decision Making in Inter-firm Networks As A Political Process, Organisation Studies, 18(3):361-384.

27. Pfeffer (1992), Managing with Power: Politics and Influence in Organisations, Boston, Mass., Harvard Business Press.

28. Dawson, P. (1994), Organisational Change: A Processual Perspective, London, Paul Chapman..

29. Morgan, G. (1997) Images of Organisations, 2nd Edition, London, Sage.

30. Buchanan, D. and Body, D. (1992), Expertise of the Change Agent, Prentice Hall, London.

31. For more details on the networking strategy at HCo, see Harris L, Coles A-M \& Dickson K (2000), Building Innovation Networks: Issues of Strategy and Expertise, Technology Analysis and Strategic Management, forthcoming.

32. The idea behind this US government policy was to 'second source' business to another supplier so that it could not be held to ransom by one firm, or experience delivery problems if a sole supplier defaulted on a contract.

33. The legacy is that FCo, even today, has to deal >cash on delivery= with a key section of its supplier base

34. Just $40 \%$ of FCo's business is currently confined to HCo. The existence of the SSA meant that one HCo engineer who visited FCo for training purposes was escorted at all times and not allowed to use the computers. In his view, the treatment he received was indicative of distrust and resentment on the part of 
FCo, and the ensuing discussion of the issue with his colleagues on returning to the UK added to the antagonism between the two companies.

35. An illustration of the cultural gap is that 'dress down Fridays' are popular at FCo. but unthinkable at HCo.

36. It is worth noting that other US firms subsequently purchased by HCo that have not had the benefit of this extended handover period have not been integrated into the group so well.

37. For example Freeman C (1991), >Networks of Innovators: A Synthesis of Research Issues $=\underline{\text { Research }}$ Policy, 20(5): 499-514; and Hamel G (1991), Competition for Competence and Inter-partner Learning Within International Strategic Alliances, Strategic Management Journal, 12 83-103

38. Hamel G and Prahalad C (1990), The Core Competence of A Corporation, Harvard Business Review, pp 79-91. 